Rev. Bras. Saúde Prod. Anim., Salvador, v.15, n.4, p.872-880 out./dez., 2014 http://www.rbspa.ufba.br ISSN 15199940

\title{
Níveis de lisina digestível para frangos de corte tipo caipira de 28 a 56 dias de idade
}

\section{Levels of digestible lysine for free-range broiler chickens from 28 to 56 days of age}

\author{
ROSA, Evellize Pereira Morara ${ }^{1}$; KIEFER, Charles ${ }^{1 *}$; SOUZA, Karina Márcia Ribeiro \\ $\mathrm{de}^{2}$; SILVA, Jardel Barbosa da ${ }^{1}$; OZELAME, Aline Marhold ${ }^{1}$; GOMES, Eva Nara \\ Oliveira $^{1}$; ROSA, Rafael Arantes ${ }^{1}$
}

\begin{abstract}
${ }^{1}$ Universidade Federal de Mato Grosso do Sul, Faculdade de Medicina Veterinária e Zootecnia, Campo Grande, Mato Grosso do Sul, Brasil.

*Endereço para correspondência: charles.kiefer@ufms.br
\end{abstract}

\section{RESUMO}

Realizou-se este estudo com o objetivo de avaliar níveis de lisina digestível para frangos tipo caipira, machos, de 28 a 56 dias de idade. Utilizou-se 720 frangos pescoço pelado de crescimento lento, da linhagem Label Rouge machos, distribuídos em delineamento inteiramente casualizado, composto por seis níveis de lisina digestível $(0,800 ; 0,850 ; 0,900$; 0,$950 ; 1,000$ e $1,050 \%$ ), seis repetições, com 20 aves cada. Os níveis de lisina digestível não influenciaram $(\mathrm{P}>0,05)$ o desempenho dos frangos nos períodos acumulados de 28 a 35 dias, 28 a 42 dias e 28 a 49 dias. Não houve efeito $(\mathrm{P}>0,05)$ no consumo de ração e conversão alimentar no período total de criação (28-56 dias). Observou-se efeito $(\mathrm{P}<0,05)$ dos níveis de lisina no peso aos 35 dias, peso final e ganho de peso dos 28 aos 56 dias de idade. Não foram observadas diferenças $(\mathrm{P}>0,05)$ para os rendimentos de carcaça e peito, pesos de gordura abdominal, coxa + sobrecoxa, dorso, asa e deposição de gordura entre os níveis de lisina digestível. Os pesos da carcaça e do peito variaram $(\mathrm{P}<0,05)$ de forma quadrática, em função dos níveis de lisina digestível. $\mathrm{O}$ aumento do peso do peito proporcionou aumento do peso da carcaça, fato explicado pelo aumento $(\mathrm{P}<0,05)$ na deposição de proteína em função dos níveis de lisina digestível que pode ser considerado um indicativo da melhora da eficiência de utilização dos nutrientes da dieta. Conclui-se que o nível de $0,910 \%$ lisina digestível atende a exigência de frangos de corte tipo caipira, de 28 a 56 das de idade.

Palavras-chave: aminoácidos, desempenho, exigência nutricional, pescoço pelado, rendimento de carcaça

\section{SUMMARY}

The objective of this study was to evaluate digestible lysine levels for free-range broiler hillbilly, from 28 to 56 days old. We used 720 naked neck chickens slow-growing Label Rouge strain males, distributed in a completely randomized design with six digestible lysine levels $(0.800,0.850,0.900,0.950,1.000$ and $1.050 \%$ ), six replicates of 20 birds each. The lysine levels did not influence $(\mathrm{P}>0.05)$ broiler performance in accumulated periods 28-35 days, 28-42 days and 28-49 days. There was no effect $(\mathrm{P}>0.05)$ of treatments on feed intake and feed conversion in the total periods (28-56 days). Effect was observed $(\mathrm{P}<0.05)$ of lysine levels on body weight at 35 days, final weight and weight gain from 28 to 56 days old. There were no differences $(\mathrm{P}>0.05)$ for carcass and breast weights of abdominal fat, thigh + drumstick, back, wing and fat deposition between the levels of lysine. The carcass weight and breast varied $(\mathrm{P}<0.05)$ quadratically depending on the levels of dietary lysine. Increased breast weight provided an increase of carcass weight, a fact explained by the increase $(\mathrm{P}<0.05)$ in protein deposition according to the level of lysine that can be considered an indication of improved efficiency of utilization of nutrients. It is concluded that the level of $0.910 \%$ meets the requirement of digestible lysine for broilers hillbilly type, from 28 to 56 of age.

Keywords: amino acids, carcass yield, naked neck, nutritional requirement, performance 


\section{INTRODUÇ̃̃̃O}

Muitos estudos têm sido realizados para avaliar as exigências de aminoácidos para frangos de corte, uma vez que esses nutrientes participam da síntese de proteínas musculares, influenciando diretamente o desempenho das aves. Contudo, existem poucos estudos visando determinar as exigências de aminoácidos de frangos de corte tipo caipira (OLIVEIRA et al., 2013).

Sabe-se que a capacidade genética para ganho das linhagens de frango tipo caipira é inferior ao do frango de corte convencional (SANTOS et al., 2005). Deve-se considerar ainda que essas linhagens possuem características diferenciadas de empenamento (NAGIB NASCIMENTO et al., 2009a). Dessa forma, a formulação de dietas nutricionalmente inadequadas em relação às exigências pode prejudicar o desempenho das aves (NAGIB NASCIMENTO et al., 2009b). Dietas com elevadas concentrações de nutrientes, além de não melhorar $o$ desempenho das aves, podem aumentar a excreção de nutrientes, acarretando em prejuízos ambientais e econômicos.

Dentre os aminoácidos, tem-se constatado que a suplementação dietética de lisina pode melhorar destacadamente a eficiência alimentar, o ganho de peso, o peso de carcaça e promover aumento do peso dos cortes nobres da carcaça (LANA et al., 2005a). Por outro lado, dietas deficientes em lisina poderão ter efeitos negativos diretos sobre o desenvolvimento muscular, afetando o desempenho, as características de carcaça das aves e a rentabilidade da atividade.

Em geral, o desempenho e o rendimento dos cortes nobres das aves de linhagens coloniais não são afetados pelo sistema de produção, mas podem ser influenciados pela genética (TAKAHASHI et al., 2006; SAVINO et al., 2007; DOURADO et al., 2009; MADEIRA et al., 2010). Dessa forma, o material genético utilizado pode ser determinante para o estabelecimento das exigências nutricionais das aves.

Quando se avalia as recomendações nutricionais de lisina para frangos de corte tipo caipira, podemos verificar que não há coerência entre as publicações disponíveis. Por sua vez, as tabelas brasileiras de composição de alimentos e exigências nutricionais (ROSTAGNO et al., 2011), que podem ser consideradas como a principal referência brasileira de recomendações nutricionais para aves e suínos, não contêm informações específicas para frangos de corte tipo caipira. Portanto, realizou-se este estudo com o objetivo de avaliar níveis de lisina digestível para frangos de corte do tipo caipira, machos, de 28 a 56 dias de idade.

\section{MATERIAL E MÉTODOS}

Foram utilizados 720 frangos de corte tipo caipira, machos pescoço pelado de crescimento lento, da linhagem Label Rouge, com 28 dias de idade e com peso inicial de 684,02g. As aves foram distribuídas em delineamento inteiramente ao acaso, com seis níveis de lisina digestível $(0,800 ; 0,850 ; 0,900$; 0,$950 ; 1,000$ e $1,050 \%$ ), seis repetições e 20 aves por repetição.

As aves foram criadas confinadas em boxes $(2,0 \times 1,5 \mathrm{~m})$ na fase inicial (um aos 27 dias), providos de comedouro e bebedouro pendular. A cama utilizada foi do tipo maravalha com oito centímetros de altura. Do $1^{\circ}$ aos 28 dias de idade, as aves foram alimentadas com uma dieta (Tabela 1) elaborada para suprir as exigências nutricionais de 
Rev. Bras. Saúde Prod. Anim., Salvador, v.15, n.4, p.872-880 out./dez., 2014 http://www.rbspa.ufba.br ISSN 15199940

acordo com recomendações propostas por Rostagno et al. (2011) para aves de reposição. Dos 28 aos 56 dias de idade, as aves tiveram acesso à área de piquete $\left(20,0 \mathrm{~m}^{2}\right)$ e foram submetidas às dietas experimentais elaboradas para conter níveis crescentes de lisina digestível, obtidos pela inclusão de L-Lisina $\mathrm{HCl}$. As aves receberam ração e água à vontade.

Tabela 1. Composições centesimal e nutricional das dietas experimentais para frangos caipiras dos 28 aos 56 dias de idade

\begin{tabular}{|c|c|c|c|c|c|c|c|}
\hline \multirow{3}{*}{ Ingredientes } & \multicolumn{7}{|c|}{ Níveis de lisina digestível (\%) } \\
\hline & \multirow{2}{*}{$\begin{array}{c}1 \text { a } 27 \text { dias } \\
0,850\end{array}$} & \multicolumn{6}{|c|}{28 a 56 dias (período experimental) } \\
\hline & & 0,800 & 0,850 & 0,900 & 0,950 & 1,000 & 1,050 \\
\hline Farelo de soja, $45 \%$ & 25,65 & 20,18 & 20,18 & 20,18 & 20,18 & 20,18 & 20,18 \\
\hline Sorgo baixo tanino & 69,60 & 74,65 & 74,65 & 74,65 & 74,65 & 74,65 & 74,65 \\
\hline Fosfato bicálcico & 1,72 & 1,78 & 1,78 & 1,78 & 1,78 & 1,78 & 1,78 \\
\hline Calcário calcítico & 1,16 & 1,14 & 1,14 & 1,14 & 1,14 & 1,14 & 1,14 \\
\hline Óleo de soja & 1,04 & 0,00 & 0,00 & 0,00 & 0,00 & 0,00 & 0,00 \\
\hline L-Lisina $\mathrm{HCl}$ & 0,09 & 0,21 & 0,26 & 0,32 & 0,38 & 0,45 & 0,51 \\
\hline DL-Metionina & 0,14 & 0,28 & 0,28 & 0,28 & 0,28 & 0,28 & 0,28 \\
\hline L-Treonina & 0,00 & 0,10 & 0,10 & 0,10 & 0,10 & 0,10 & 0,10 \\
\hline L-Triptofano & 0,00 & 0,05 & 0,05 & 0,05 & 0,05 & 0,05 & 0,05 \\
\hline Mistura mineral $^{1}$ & 0,10 & 0,10 & 0,10 & 0,10 & 0,10 & 0,10 & 0,10 \\
\hline Mistura vitamínica $^{2}$ & 0,10 & 0,10 & 0,10 & 0,10 & 0,10 & 0,10 & 0,10 \\
\hline Sal comum & 0,41 & 0,41 & 0,41 & 0,41 & 0,41 & 0,41 & 0,41 \\
\hline Amido & 0,00 & 1,00 & 0,95 & 0,89 & 0,83 & 0,76 & 0,70 \\
\hline Total & 100,00 & 100,00 & 100,00 & 100,00 & 100,00 & 100,00 & 100,00 \\
\hline \multicolumn{8}{|c|}{ Composição calculada $^{3}$} \\
\hline $\mathrm{EM}, \mathrm{kcal} \mathrm{kg}^{-1}$ & 2.900 & 2.900 & 2.900 & 2.900 & 2.900 & 2.900 & 2.900 \\
\hline Proteína bruta, \% & 18,00 & 16,50 & 16,50 & 16,50 & 16,50 & 16,50 & 16,50 \\
\hline Lisina dig., $\%$ & 0,850 & 0,800 & 0,850 & 0,900 & 0,950 & 1,000 & 1,050 \\
\hline Met+Cist dig., $\%$ & 0,620 & 0,700 & 0,700 & 0,700 & 0,700 & 0,700 & 0,700 \\
\hline Treonina dig., $\%$ & 0,580 & 0,600 & 0,600 & 0,600 & 0,600 & 0,600 & 0,600 \\
\hline Triptofano dig., $\%$ & 0,210 & 0,220 & 0,220 & 0,220 & 0,220 & 0,220 & 0,220 \\
\hline Arginina dig., $\%$ & 1,030 & 0,910 & 0,910 & 0,910 & 0,910 & 0,910 & 0,910 \\
\hline Valina dig., \% & 0,790 & 0,700 & 0,700 & 0,700 & 0,700 & 0,700 & 0,700 \\
\hline Cálcio, \% & 0,940 & 0,940 & 0,940 & 0,940 & 0,940 & 0,940 & 0,940 \\
\hline Fósforo disp., \% & 0,430 & 0,430 & 0,430 & 0,430 & 0,430 & 0,430 & 0,430 \\
\hline Sódio, \% & 0,180 & 0,180 & 0,180 & 0,180 & 0,180 & 0,180 & 0,180 \\
\hline
\end{tabular}

${ }^{1}$ Níveis por kg de ração: ferro, $5.000 \mathrm{mg}$; cobre, $70.000 \mathrm{mg}$; cobalto, 0,2 g; manganês, $60.000 \mathrm{mg}$; zinco, $50.000 \mathrm{mg}$; iodo, $1.250 \mathrm{mg}$; selênio, $200 \mathrm{mg}$ e excipiente q.s.p., $1000 \mathrm{~g}$.

${ }^{2}$ Níveis por kg de ração: Vit. A, 1.500.000UI; Vit. D3, 500.000UI; Vit. E, 3.000UI; Vit. B1, 250mg; Vit. B2, $1.125 \mathrm{mg}$; Vit. B6, $375 \mathrm{mg}$; ácido pantotênico, 10g; Vit. K3, 200g; ácido nicotínico,7.500 mg; Vit. B12, $3.0000 \mathrm{mg}$; ácido fólico, $1.375 \mathrm{mg}$; biotina, $12,5 \mathrm{mg}$; colina, $81.250 \mathrm{mg}$ e excipiente q.s.p., $1000 \mathrm{~g}$.

${ }^{3}$ Composição nutricional estimada segundo informações contidas em Rostagno et al. (2011).

A temperatura e a umidade relativa ambiental foram monitoras diariamente às 7:00, 12:00 e 17:00 horas durante todo o período experimental, por meio de um conjunto de termômetros de máxima e mínima, de bulbo seco e bulbo úmido e de globo negro instalados no centro do galpão. Durante o período experimental, as temperaturas mínima e máxima registradas foram de 
22,9 e $31,5^{\circ} \mathrm{C}$, respectivamente. As umidades relativas do ar mínima e máxima foram de 46,7 e $74,7 \%$, respectivamente.

As aves foram pesadas aos $28 \mathrm{e}$ semanalmente aos 35; 42; 49 e 56 dias. Foram avaliados dados de desempenho como o consumo de ração diário e o ganho de peso diário e conversão alimentar. $\mathrm{O}$ consumo de ração foi determinado a partir do somatório da quantidade de ração fornecida, subtraindo-se as sobras de ração dos comedouros ao final do experimento. $\mathrm{O}$ resultado obtido foi dividido pelo número de dias em que os animais permaneceram no experimento, obtendo-se o consumo de ração diário.

Para a determinação do ganho de peso diário, o peso final foi subtraído pelo peso inicial das aves e o resultado dividido pelo número de dias do período experimental. A conversão alimentar foi obtida pela divisão do consumo de ração diário pelo ganho de peso diário. $\mathrm{O}$ ganho de peso e a conversão alimentar foram corrigidos pela mortalidade, segundo metodologia descrita por Sakomura \& Rostagno (2007).

Ao final do período experimental, após jejum de sólidos de 12 horas, duas aves de cada repetição de peso médio $( \pm 5 \%)$ foram abatidas. As aves foram dessensibilizadas por deslocamento cervical e sangria. As características de carcaça avaliadas foram calculadas em relação ao peso corporal após jejum, sendo os rendimentos de cortes $\mathrm{e}$ gordura abdominal, calculados em relação ao peso da carcaça depenada e eviscerada. Foi considerada gordura abdominal todo $\mathrm{o}$ tecido adiposo aderido ao redor da cloaca, moela e dos músculos abdominais adjacentes. Além das características de desempenho zootécnico e de carcaça, foram determinadas as deposições de proteína e gordura corporal durante o período.

$\mathrm{O}$ abate aos 28 dias e 56 dias as carcaças inteiras das aves abatidas, sem as vísceras e o sangue, foram trituradas individualmente e homogeneizadas. Após tal procedimento, retirou-se uma amostra de $50 \mathrm{~g}$ para análise. As análises bromatológicas das amostras das carcaças (matéria seca, umidade, extrato etéreo e proteína bruta) foram realizadas de acordo com as metodologias descritas por Silva \& Queiroz (2002). Os valores de composição das carcaças dos animais no início e no fim do período experimental foram utilizados para a determinação das deposições de proteína e de gordura diárias na carcaça. Os dados das variáveis de desempenho, características de carcaça e composição corporal foram submetidas à análise de covariância, sendo $o$ peso inicial estabelecido como covariável. Posteriormente, foram realizadas análises de regressão, em nível de $5 \%$ de probabilidade.

\section{RESULTADOS E DISCUSSÃO}

O consumo de ração, o ganho de peso e a conversão alimentar, no período de 28 aos 35 dias de idade, não foram afetados $(\mathrm{P}>0,05)$ pelos níveis de lisina digestível (Tabela 2). Observou-se variação quadrática $(\mathrm{P}<0,05)$ do peso das aves aos 35 dias de idade, que aumentou até o nível de $0,898 \%$ de lisina digestível de acordo com a equação $\hat{\mathrm{Y}}=343,74+2943,3 \mathrm{x}-1638 \mathrm{x}^{2}$, $\mathrm{R}^{2}=0,78$.

No período de 28 aos 42 e 28 e 49 dias de idade, os níveis de lisina digestível não influenciaram $(\mathrm{P}>0,05)$ o peso final, o consumo de ração, o ganho de peso e a conversão alimentar das aves. Por sua 
Rev. Bras. Saúde Prod. Anim., Salvador, v.15, n.4, p.872-880 out./dez., 2014 http://www.rbspa.ufba.br ISSN 15199940

vez, Amarante Junior et al. (2005) verificaram efeito quadrático dos níveis de lisina sobre a conversão alimentar de frangos de corte, nos períodos de 22 a 42 e de 43 a 49 dias, estimando o nível de lisina de $1,140 \%$ para a melhor conversão alimentar.

No período total do experimento, 28 aos 56 dias de idade, não foi constatado efeito $(\mathrm{P}>0,05)$ dos níveis de lisina digestível sobre o consumo de ração e conversão alimentar. Resultados semelhantes também foram verificados por Valério et al. (2003) e Lana et al. (2005a) que constataram que o consumo de ração dos frangos de corte aos 42 dias não foi influenciado pela inclusão de lisina digestível na dieta.

Tabela 2. Desempenho de frangos de corte tipo caipira, machos submetidos às dietas contendo diferentes níveis de lisina digestível dos 28 aos 56 dias de idade

\begin{tabular}{|c|c|c|c|c|c|c|c|c|}
\hline \multirow{2}{*}{ Variáveis } & \multicolumn{6}{|c|}{ Níveis de lisina digestível (\%) } & \multirow{2}{*}{ Valor P } & \multirow{2}{*}{$\begin{array}{l}\text { CV } \\
(\%)\end{array}$} \\
\hline & 0,800 & 0,850 & 0,900 & 0,950 & 1,000 & 1,050 & & \\
\hline \multicolumn{9}{|c|}{$28-35$ dias } \\
\hline Peso inicial, $g$ & 679,0 & 688,5 & 689,5 & 686,3 & 683,5 & 677,3 & - & - \\
\hline Consumo de ração, $\mathrm{g}$ & 607,4 & 642,9 & 635,3 & 581,6 & 640,4 & 653,3 & 0,163 & 7,98 \\
\hline Ganho de peso, $g$ & 280,8 & 293,2 & 287 & 278 & 288,3 & 260,3 & 0,221 & 8,19 \\
\hline Conversão alimentar & 2,18 & 2,19 & 2,21 & 2,09 & 2,23 & 2,63 & 0,225 & 16,94 \\
\hline Peso final, $\mathrm{g}^{*}$ & 959,8 & 981,7 & 976,5 & 964,3 & 971,8 & 937,7 & 0,04 & 2,38 \\
\hline \multicolumn{9}{|c|}{$28-42$ dias } \\
\hline Consumo de ração, $\mathrm{g}$ & 1317 & 1391 & 1323 & 1283 & 1325 & 1343 & 0,141 & 4,8 \\
\hline Ganho de peso, g & 574,3 & 584,3 & 589,2 & 576,5 & 575,8 & 553,5 & 0,272 & 4,46 \\
\hline Conversão alimentar & 2,31 & 2,38 & 2,24 & 2,22 & 2,3 & 2,44 & 0,088 & 5,92 \\
\hline Peso final, $\mathrm{g}$ & 1253 & 1273 & 1279 & 1263 & 1259 & 1231 & 0,053 & 2,04 \\
\hline \multicolumn{9}{|c|}{$28-49$ dias } \\
\hline Consumo de ração, $\mathrm{g}$ & 2137 & 2183 & 2200 & 2203 & 2195 & 2164 & 0,813 & 4,31 \\
\hline Ganho de peso, g & 911,3 & 938,3 & 928,8 & 930,7 & 887 & 896,2 & 0,314 & 4,92 \\
\hline Conversão alimentar & 2,35 & 2,32 & 2,37 & 2,36 & 2,51 & 2,41 & 0,461 & 6,89 \\
\hline Peso final, $\mathrm{g}$ & 1590 & 1627 & 1618 & 1617 & 1571 & 1574 & 0,156 & 2,82 \\
\hline \multicolumn{9}{|c|}{$28-56$ dias } \\
\hline Consumo de ração, $\mathrm{g}$ & 2925 & 2974 & 2898 & 3006 & 2973 & 2899 & 0,388 & 3,56 \\
\hline Ganho de peso, $\mathrm{g}^{*}$ & 1232 & 1255 & 1209 & 1292 & 1242 & 1192 & 0,043 & 4,21 \\
\hline Conversão alimentar & 2,37 & 2,36 & 2,39 & 2,33 & 2,39 & 2,42 & 0,728 & 4,12 \\
\hline Peso final, $\mathrm{g}^{*}$ & 1911 & 1943 & 1898 & 1978 & 1926 & 1869 & 0,026 & 2,71 \\
\hline
\end{tabular}

*Efeito quadrático $(\mathrm{P}<0,05)$.

Por outro lado, vários estudos como o de Valério et al. (2003) e Lana et al. (2005a; 2005b) verificaram melhora na conversão alimentar de frangos de corte em função do aumento dos níveis de lisina digestível nas dietas. $\mathrm{O}$ fato de não ter ocorrido melhora da conversão alimentar, no presente estudo, pode ser um indicativo da menor capacidade de utilização da proteína e dos nutrientes da dieta para ganho de peso da linhagem utilizada em relação ao frango de corte convencional.

Os níveis de lisina digestível influenciaram $(\mathrm{P}<0,05)$ de forma quadrática o peso final e o ganho de peso das aves dos 28 aos 56 dias de idade, aumentando até os níveis de 0,909 e $0,908 \%$, de acordo com as equações $\hat{Y}=-845,03+6137 x-3373 x^{2}, R^{2}$ 
$=0,64$ e $\hat{Y}=-975,49+4915 x-2704,8 x^{2}$, $\mathrm{R}^{2}=0,63$, respectivamente. Por sua vez, Nagib Nascimento (2009a) testou níveis de lisina digestível $(0,750 ; 0,870 ; 0,990$ e $1,110 \%$ ) para aves caipiras de ambos os sexos, no período de 28 aos 56 dias, e verificou que a melhor resposta para ganho de peso foi obtida com o nível estimado de $1,056 \%$.

Assim como a deficiência, o excesso de alguns aminoácidos como a lisina também pode prejudicar o desempenho das aves. O peso corporal das aves aumenta à medida que aumenta o nível de lisina na dieta, até atingir um nível ótimo, a partir do qual ocorre redução no peso corporal das aves (ISHIBAHI \& YONEMOCHI, 2002). Fato evidenciado, no presente estudo, em que se observou esse efeito sobre o peso das aves dos 28 aos 35 dias e dos 28 aos 56 dias de idade.
Os níveis de lisina digestível não influenciaram $(\mathrm{P}>0,05)$ os rendimentos de carcaça e peito, pesos de gordura abdominal, coxa + sobrecoxa, dorso, asa e deposição de gordura diária na carcaça (Tabela 3). O rendimento de carcaça médio, obtido no presente estudo foi de $65,44 \%$, valor similar àquele reportado por Lana et al. (2005a) que, ao estudarem variações dos níveis de lisina digestível de 0,880 a $1,120 \%$ para frangos de corte machos, de 22 a 42 dias de idade, não encontraram variação no rendimento de carcaça. Em estudo para avaliar as exigências de lisina digestível, Valério et al. (2003) não observaram efeito dos níveis de lisina digestível sobre o rendimento de carcaça de frangos de corte (22 a 42 dias de idade), entretanto observaram aumento linear no peso absoluto e no rendimento de peito das aves.

Tabela 3. Características de carcaça de frangos de corte machos tipo caipira submetidos a dietas contendo diferentes níveis de lisina digestível de 28 a 56 dias de idade

\begin{tabular}{|c|c|c|c|c|c|c|c|c|}
\hline \multirow{2}{*}{ Variáveis } & \multicolumn{6}{|c|}{ Níveis de lisina digestível (\%) } & \multirow{2}{*}{ Valor P } & \multirow{2}{*}{$\begin{array}{l}\text { CV } \\
(\%)\end{array}$} \\
\hline & 0,800 & 0,850 & 0,900 & 0,950 & 1,000 & 1,050 & & \\
\hline Peso de carcaça, g* $^{*}$ & 1.197 & 1.245 & 1.188 & 1.244 & 1.219 & 1.173 & 0,011 & 4,76 \\
\hline Rendimento de carcaça, \% & 64,96 & 65,86 & 65,43 & 65,58 & 65,62 & 65,19 & 0,892 & 2,98 \\
\hline Gordura abdominal, g & 0,035 & 0,039 & 0,037 & 0,038 & 0,045 & 0,037 & 0,639 & 37,92 \\
\hline Peito, $g^{*}$ & 321,1 & 345,5 & 331,2 & 343,6 & 339,4 & 313,8 & 0,007 & 7,09 \\
\hline Rendimento de peito, $\%$ & 26,77 & 27,74 & 27,86 & 27,61 & 27,82 & 26,76 & 0,072 & 4,47 \\
\hline Coxa e sobrecoxa, $g$ & 418,9 & 426,6 & 402 & 428,5 & 408,3 & 405,2 & 0,078 & 6,52 \\
\hline Dorso, $\mathrm{g}$ & 289,8 & 303,3 & 289,6 & 300,8 & 296,6 & 287,8 & 0,25 & 6,56 \\
\hline Asa, g & 167,6 & 169,7 & 165,8 & 168,6 & 166,6 & 166,00 & 0,893 & 5,57 \\
\hline Deposição de proteína, g/dia* & 21,48 & 22,03 & 18,92 & 22,16 & 22,76 & 20,11 & 0,001 & 6,20 \\
\hline Deposição de gordura, g/dia & 14,86 & 15,79 & 16,97 & 17,48 & 17,85 & 16,26 & 0,256 & 17,07 \\
\hline
\end{tabular}

*Efeito quadrático $(\mathrm{P}<0,05)$.

Observou-se variação quadrática $(\mathrm{P}<0,05)$ do peso de carcaça $(\hat{\mathrm{Y}}=-$ $\left.818,52+4509,9 \mathrm{x}-2482,3 \mathrm{x}^{2}, \quad \mathrm{R}^{2}=0,68\right)$ e do peso de peito $(\hat{\mathrm{Y}}=-915,93+2747 \mathrm{X}$ $\left.1498 \mathrm{x}^{2}, \mathrm{R}^{2}=0,67\right)$ e da deposição de proteína diária na carcaça $(\hat{\mathrm{Y}}=-$ $\left.74,851+214 x-117,29 x^{2}, \quad R^{2}=0,68\right) \quad$ em função do aumento dos níveis de lisina digestível das dietas, sendo que os níveis que otimizaram as respostas para essas variáveis foram 0,$908 ; 0,916 \mathrm{e}$ $0,876 \%$, respectivamente.

Pode-se inferir que o aumento do peso de carcaça, observado no presente 
Rev. Bras. Saúde Prod. Anim., Salvador, v.15, n.4, p.872-880 out./dez., 2014 http://www.rbspa.ufba.br ISSN 15199940

estudo, está diretamente relacionado com o aumento do peso de peito. Esse resultado pode ser explicado pelo aumento da deposição de proteína na carcaça em razão do aumento da concentração de lisina digestível na dieta que também pode ser considerado como um indicativo da melhoria do balanço de aminoácidos. Essa resposta é coerente a observada em outros estudos como o de Trindade Neto et al. (2009) que avaliando frangos de corte machos, verificaram aumento linear da deposição proteica na carcaça de acordo com o aumento dos níveis de lisina digestível da dieta, sendo que o nível de lisina estabelecido pelos pesquisadores foi de $1,100 \%$.

De acordo com os resultados de desempenho e de carcaça obtidos, no presente estudo, pode-se inferir que o nível de $0,910 \%$ de lisina digestível otimiza o ganho de peso e peso final das aves e proporciona máximas respostas para os pesos de carcaça e de peito. Esse resultado é inferior ao nível de $1,006 \%$ estabelecido por Nagib Nascimento et al. (2009a), mas próximo ao nível de $0,950 \%$ de lisina total recomendado pelo Manual de Manejo Linha Colonial (2011) para a mesma fase avaliada neste estudo.

Portanto, conclui-se que o nível de $0,910 \%$ de lisina digestível atende a exigência de frangos de corte tipo caipira de crescimento lento, machos de 28 a 56 dias de idade.

\section{COMITÊ DE ÉTICA E BIOSSEGURANÇA}

Procedimentos aprovados pela comissão de ética no uso de animais/UFMS, sob protocolo $n^{\circ} 230 / 2009$.

\section{REFERÊNCIAS}

AMARANTE JÚNIOR, V.S.; COSTA, F.G.P.; BARROS, L.R.; NASCIMENTO, G.A.J.; BRANDÃO, P.A.; SILVA, J.H.V.; PEREIRA, W.E.; NUNES, R.V.; COSTA, J.S.; RIBEIRO, M.L.G. Níveis de lisina para frangos de corte nos períodos de 22 a 42 e de 43 a 49 dias de idade, mantendo a relação metionina+cistina. Revista

Brasileira de Zootecnia, v.34, p.11881194, 2005.

DOURADO, L.R.B.; SAKOMURA, N.K.; NAGIB NASCIMENTO, D.C.; DORIGAM, J.C.; MARCATO, S.M.; FERNANDES, K.J.B. Crescimento e desempenho de linhagens de aves pescoço pelado criadas em sistema semi-confinamento. Ciência e

Agrotecnologia, v.33, p.875-881, 2009.

ISHIBAHI, T.; YONEMOCHI, C. Possibility of amino acid nutrition in broiler. Animal Science Journal, v.73, p.155-165, 2002.

LANA, S.R.V.; OLIVEIRA, R.F.M.; DONZELE, J.L.; GOMES, P.C.; VIEIRA VAZ, R.B.M.; REZENDE, W.O. Níveis de lisina digestível em rações para frangos de corte de 22 a 42 dias de idade, mantidos em ambiente de temoneutralidade. Revista Brasileira de Zootecnia, v.34, p.1624-1632, 2005a.

LANA, S.R.V.; OLIVEIRA, R.F.M.; DONZELE, J.L.; ALBINO, L.F.T.; VIEIRA VAZ, R.G.M.; REZENDE, W.O. Níveis de lisina digestível em rações para frangos de corte de 1 a 21 dias de idade mantidos em ambiente de termoneutralidade. Revista Brasileira de Zootecnia, v.34, p.1614-1623, 2005 b. 
Rev. Bras. Saúde Prod. Anim., Salvador, v.15, n.4, p.872-880 out./dez., 2014 http://www.rbspa.ufba.br ISSN 15199940

MADEIRA, L.A.; SARTORI, J.R.; ARAUJO, P.C.; PIZZOLANTE, C.C.; SALDANHA, E.S.P.B.; PEZZATO, A.C. Avaliação do desempenho e do rendimento de carcaça de quatro linhagens de frangos de corte em dois sistemas de criação. Revista Brasileira de Zootecnia, v.39, p.2214-2221, 2010.

MANUAL de manejo linha colonial. [s.n.]: Globoaves, 2011.23p. Disponível em:

$<$ www2.globoaves.com.br/downloads/do wnload.php? file...pdf $>$. Acesso em: 24 nov. 2014.

NAGIB NASCIMENTO, D.C.; SAKOMURA, N.K.; SIQUEIRA, J.C.; PINHEIRO, S.R.F.; FERNANDES, J.B.K.; FURLAN, R.L. Exigências de metionina + cistina digestível para aves de corte ISA Label criadas em semiconfinamento. Revista Brasileira de Zootecnia, v.38, p.869-878, 2009a.

NAGIB NASCIMENTO, D.C.; SAKOMURA, N.K.; SIQUEIRA, J.C.; DOURADO, L.R.B.; FERNANDES, J.B.K.; MALHEIROS, E.B. Exigências de lisina digestível para aves de corte da linhagem ISA Label criadas em semiconfinamento. Arquivos Brasileiros de Medicina Veterinária e Zootecnia, v.61, p.1128-1138, 2009b.

OLIVEIRA, H.G.; CARRIJO, A.S.; KIEFER, C.; GARCIA, E.R.M.; OLIVEIRA, J.A.; SILVA, J.B.; FREITAS, L.N.; HORING, S.F. Lisina digestível em dietas de baixa proteína para frangos de corte tipo caipira de um aos 28 dias. Arquivo Brasileiro de Medicina Veterinária e Zootecnia, v.65, p.497-504, 2013.
ROSTAGNO, H.S.; ALBINO, L.F.T.;

DONZELE, J.L.; GOMES, P.C.;

OLIVEIRA, R.F.M.; LOPES, D.C.; FERREIRA, A.S.; BARRETO, S.L.T.; EUCLIDES, R.F. Tabelas brasileiras para aves e suínos: composição de alimentos e exigências nutricionais. 2.ed. Viçosa: Universidade Federal de Viçosa, 2011.252p.

SAKOMURA, N.K.; ROSTAGNO, H.S. Métodos de pesquisa em nutrição de monogástricos. Jaboticabal: FUNEP: 2007.283p.

SANTOS, A.L.; SAKOMURA, N.K.; FREITAS, E.R.; FORTES, C.M.L.S.; CARRILHO, E.N.V.M.; FERNANDES, J.B.K. Estudo do crescimento, desempenho, rendimento de carcaça e qualidade de carne de três linhagens de frango de corte. Revista Brasileira de Zootecnia, v.34, p.1589-1598, 2005.

SAVINO, V.J.M.; COELHO, A.A.D.; ROSÁRIO, M.F.; SILVA, M.A.N. Avaliação de materiais genéticos visando à produção de frango caipira em diferentes sistemas de alimentação.

Revista Brasileira de Zootecnia, v.36, p.578-583, 2007.

SILVA, D.J.; QUEIROZ, A.C. Análise de alimentos: métodos químicos e biológicos. 3.ed. Viçosa, MG: UFV, 2002. 235p.

TAKAHASHI, S.E.; MENDES, A.A.; SALDANHA, E.S.P.B.; PIZZOLANTE, C.C.; PELICIA, K.; GARCIA, R.G.; PAZ, I.C.L.A.; QUINTEIRO, R.R. Efeito do sistema de criação sobre o desempenho e rendimento de carcaça de frangos de corte tipo colonial. Arquivo Brasileiro de Medicina Veterinária e Zootecnia, v.58, p.624-632, 2006. 
Rev. Bras. Saúde Prod. Anim., Salvador, v.15, n.4, p.872-880 out./dez., 2014 http://www.rbspa.ufba.br ISSN 15199940

TRINDADE NETO, M.A.; TAKEARA, P.; TOLEDO, A.L.; KOBASHIGAWA, E.; ALBUQUERQUE, R.; ARAUJO, L.F. Níveis de lisina digestível para frangos de corte machos no período de 37 a 49 dias de idade. Revista Brasileira de Zootecnia, v.38, p.508-514, 2009.

VALÉRIO, S.R.; OLIVEIRA, R.F.M.; DONZELE, J.L.; GOMES, P.C.; APOLONIO, L.R.; RESENDE, W.O. Níveis de lisina digestível em rações, em que se manteve ou não a relação aminoacídica, para frangos de corte de 22 a 42 dias de idade, mantidos em estresse por calor. Revista Brasileira de Zootecnia, v.32, p.372-382, 2003.

Data de recebimento: 05/02/2014

Data de aprovação: 24/10/2014 